\title{
ÉLISÉE RECLUS ¿UN PROTO-ECOLOGISTA?
}

\author{
Miriam Hermi Zaar* \\ Universidad de Barcelona
}

Resumen: Élisée Reclus nos dejó un gran legado con el que enfoca al ser humano como parte intrínseca de la naturaleza. Este manuscrito, elaborado a partir de los textos de Reclus y de autores estudiosos de su obra, tiene como propósito examinar las reflexiones reclusianas sobre las relaciones sociedad-naturaleza en el espacio y en el tiempo, desde un movimiento dialéctico, y como éstas pueden deteriorar el medio natural. En sus análisis, engendrado a partir de un planteamiento que refuta el enfoque determinista, Reclus hace hincapié en los límites de la naturaleza y defiende la necesidad de formar una conciencia medioambiental, con la finalidad de comprenderla mejor y actuar sobre la misma, preservando su equilibrio. Por sus aportaciones metodológicas a los estudios geográficos y a la ecología, con las que brinda al desarrollo una visión ecológica del mundo y en particular al razonamiento ecológico-social, Reclus merece ser considerado un proto-ecologista.

Palabras clave: Élisée Reclus; proto-ecología; relaciones ser humano-naturaleza en el espacio y en el tiempo; conciencia medioambiental.

\section{ÉLISÉE RECLUS, A PROTOECOLOGIST?}

Abstract: Élisée Reclus gave us a great legacy through focuses the human being as an intrinsic part of the nature. This manuscript elaborated from Reclus texts and authors who study their work, purposes to examine reclusian reflections about society-nature relations in the space and in the time from a dialectical movement, and how these ones can deteriorate the natural environment. In his analyses, begotten from an approach that refutes the deterministic, Reclus emphasizes the limits of nature and defends the need of forming an environmental awareness, so as to better understand it and act on it, preserving its equilibrium. For his methodological contributions to geographical studies and ecology, through which ones he provides to development an ecological view of the world and in particular to ecological-social reasoning, Reclus merits to be considered a proto-ecologist. Keywords: Élisée Reclus; protoecology; human-nature relationships in space and time; environmental awareness.

\section{ÉLISÉE RECLUS, UM PROTO-ECOLOGISTA?}

Resumo: Élisée Reclus nos deixou um grande legado, no qual enfoca o ser humano como parte intrínseca da natureza. Este texto, elaborado a partir de textos de Reclus e de autores estudiosos de sua obra, tem como propósito examinar as reflexões reclusianas sobre as relações sociedade-natureza no espaço e no tempo desde um movimento dialético, e como estas podem deteriorar o meio natural. Nas suas análises, engendradas a partir de uma abordagem que refuta o enfoque determinista, Reclus enfatiza os limites da natureza e defende a necessidade de formar uma consciência meio ambiental, com a finalidade de compreendê-la melhor e atuar sobre a mesma preservando o seu equilíbrio. Por suas contribuições metodológicas aos estudos geográficos e à ecologia, nas quais brinda ao desenvolvimento uma visão ecológica do mundo e em particular ao raciocínio ecológicosocial, Reclus merece ser considerado um proto-ecologista.

Palavras-chave: Élisée Reclus; proto-ecologia; relações ser humano-natureza no espaço e no tempo; consciência meio ambiental. 
Introducción

Élisée Reclus (1830-1905) fue un geógrafo-viajero incansable que disfrutaba inmensamente del contacto con la naturaleza, "un flâneur de la naturaleza" que aprovechaba sus viajes para observar, describir y analizar los elementos que la componen, sus movimientos naturales y los ocasionados por la acción antrópica.

Discípulo de Karl Ritter y asiduo lector de las obras de Alexander von Humboldt, Reclus nació el 1 de marzo de 1830 en Saint-Foy-la-Grande, una pequeña ciudad en los márgenes del río Dordoña, Francia. Es muy probable que su estrecha relación con la naturaleza se haya manifestado desde pequeño. Este interés se transformó en uno de sus principales objetos de estudio en los viajes que hizo por diversos continentes, y del que resultó la elaboración de su método de análisis y la redacción de una extensa obra en la que la relación entre el hombre y el medio está muy presente.

Su primer contacto con la Geografía se produjo en 1851, cuando decidió inscribirse en la Universidad de Berlín, donde cursó asignaturas y conoció a Karl Ritter y a otros geógrafos.

Su permanencia en Berlín finalizó en el verano de 1852, cuando, acompañado por su hermano Elías, emprendió, un largo viaje a pie, desde Estrasburgo a la residencia de sus padres, en Orthez (sur de Francia). En este trayecto, Élisée aprovechó para observar y hacer apuntes sobre las características paisajísticas, las múltiples relaciones entre los seres humanos y la naturaleza y el resultado de las mismas en lo que se refiere a la organización de las comunidades aldeanas. Fue en circunstancias como éstas, cuando comenzó a engendrarse el método de análisis reclusiano, en el que defiende que la sociedad y la naturaleza forman un conjunto armónico.

A finales de 1852, Reclus se exiló en Inglaterra a causa de su participación en un intento de resistencia al golpe de Estado de Napoleón III. Después de una breve estancia en Londres, aceptó un trabajo de subadministrador en una hacienda al sur de Dublín, donde se dedicó a las actividades agrícolas y aprovechó su tiempo libre para conocer el Oeste irlandés, una circunstancia que lo llevó, por primera vez, a pensar en escribir un libro de Geografía Física.

En diciembre de 1852 Élisée partió de Liverpool hacia Nueva Orleans, donde trabajó como preceptor en la casa de un terrateniente y realizó varios viajes por el río Mississippi y el estado de Michigan.

Ávido por conocer nuevas tierras, en diciembre de 1855 viajó a Nueva Granada (actual Colombia), haciendo escalas en La Habana y Panamá. Estuvo en la Sierra Nevada de Santa Marta, donde realizó varios itinerarios de estudio, identificando y relacionando diferentes tipos de climas, de vegetación y de cultivos. Impresionado con la inmensidad de las tierras desocupadas y con su fertilidad, planteó fundar una colonia agrícola llevando europeos a esta zona, pero las dificultades encontradas y el hecho de haber contraído la malaria le hicieron desistir de la idea.

Reclus regresó a Francia con un gran volumen de apuntes e interesado en la Geografía. Fue invitado a elaborar las guías turísticas Guides Joanne lo que le posibilitó recorrer Francia, Alemania, Suiza, Italia y España y acumular una gran cantidad de informaciones que le llevaron a redactar artículos, cómo "Los volcanes y los movimientos sísmicos terrestres", "Sicilia y la erupción del Etna", "Las playas y los fiordos", "El océano: estudios de física marítima”, "El viaje a la Sierra Nevada" o el Atlas de Colombia, entre otros, que fueron publicados en conceptuadas revistas.

En 1862 ingresó en la Société de Géographie de París, lo que le posibilitó tener acceso a su importante biblioteca.

Este intenso trabajo le llevó a concluir en 1869 la primera de sus tres obras más importantes, La Terre. Description des phénoménes de la vie du globe elaborada en dos tomos (I. Les continents; II. L'Océan. L'atmosphère. La vie), en los que, al presentar la Tierra como un ambiente dinámico, en constante movimiento (erosión, procesos volcánicos activos, terremotos, huracanes, playas, meandros, etc.) dejó explícitas las únicas leyes que reconocía, las de la naturaleza, vinculadas a la existencia humana.

En 1871 Élisée Reclus participó en la Comuna de París, hecho que le llevó a un tribunal de justicia, frente al que asumió sus actos y posiciones político-ideológicas, así justificadas más tarde:

[...] mi conciencia me mostraba un camino que yo creía ser el del deber. Si no lo hubiera seguido me habría despreciado a mí mismo y llevaría ahora una existencia miserable. Por lo menos puedo decirme ahora que fui sincero y fiel a mis convicciones. (Correspondance, tomo II, p. 91, apud GIBLIN, 1986, p. 45)

Reclus fue condenado a un exilio de diez años en Suiza, durante el que elaboró su segunda gran obra titulada Nouvelle Géographia Universelle. La Terre et les hommes con casi 18.000 páginas, que fue publicada en diecinueve volúmenes, cada uno abordando un área geográfica del globo. Para su redacción, fueron fundamentales los viajes de estudios que realizó durante su exilio, por diversos países europeos (España, Portugal, Hungría Italia), del norte y del sur de África, de Asia Menor (Turquía) y americanos (Estados Unidos y Canadá), 
visitando bibliotecas y universidades, colectando datos y observando el paisaje. Para Reclus, hacer geografía era, ante todo, moverse; por esto, siempre que le fue posible realizaba estos recorridos caminando.

En Bruselas, Reclus impartió, a partir de 1894, la asignatura de Geografía con la siguiente estructura: Geografía e Historia de la Geografía, Nociones Elementares de Geografía Física y Geografía Física, Geografía en el Tiempo y en el Espacio. También fundó en la Nouvelle Université Libre de Bruxelles un Instituto Geográfico, creó la Societé de Cartes et Travaux Géographiques Elisée Reclus y organizó una importante biblioteca.

Su última gran obra, L'Homme et la Terre publicada entre 1906 y 1908 en seis volúmenes y 4.000 páginas es considerada su obra síntesis y la que mejor refleja su método de análisis, porque no fue sometida a censura, como las anteriores. En ella, analiza los orígenes del hombre y del planeta, su pasado y devenir a partir de un movimiento en el que "el hombre experimenta su relación con el espacio, donde acontece perpetuamente el diálogo entre el lugar, visto con toda su intimidad, y el planeta, bajo el gobierno de las influencias cósmicas" (CREAGH, 2010, p. 15).

Éliseé Reclus concibe, en esta obra dedicada a la geografía social, tres grandes conceptos, que debido a su constancia se podrían reconocer como "leyes": la lucha de clases (como producto de las contradicciones sociales); la búsqueda del equilibrio (en un movimiento que pende para uno o para otro lado y es responsable de los períodos de progreso y retroceso social); y la decisión soberana del individuo (reconociendo que cualquier evolución social solo puede ser impulsada a través del esfuerzo individual y de su decisión soberana). Su unidad dialéctica forma la concepción del método reclusiano (ZAAR, 2015a, p. 21-24).

Con base en los textos publicados en estas y otras obras, y también en revistas científicas, analizamos el pensamiento de Élisée Reclus respecto a la naturaleza, al medioambiente, a las relaciones hombre-naturaleza (la acción antrópica sobre el medio), desde su método de estudio, así como, sus contribuciones a lo que hoy es la ciencia de la ecología.

Para ello, organizamos este manuscrito en cuatro partes, además de esta introducción y de las conclusiones. Dedicamos una primera parte a averiguar cómo, a través de sus publicaciones, se constata su gran amor y respeto por la naturaleza, concibiéndola como parte de un movimiento armónico. A continuación, trataremos de elucidar sus conexiones teóricas con algunas de las corrientes del pensamiento del siglo XIX y cómo éstas contribuyeron a la formación de conceptos, como los que enfocan al ser humano como parte intrínseca de la naturaleza. En un tercer apartado nos centramos en examinar las reflexiones reclusianas en lo concerniente a las relaciones ser humano-naturaleza y como éstas pueden deteriorar el medio natural. En el apartado siguiente, nos proponemos entrar en el debate acerca de la 'visión determinista' de Reclus, que algunos insisten en apuntar, sin tener presente su método de análisis, ideado a temprana edad y desarrollado durante toda su trayectoria geográfica. Dedicamos las reflexiones finales, a examinar cómo, sus contribuciones sobre el medioambiente y la relación sociedad-naturaleza pueden, en el contexto actual, definir a Éliseé Reclus, como un proto-ecologista.

\section{Élisée Reclus y su sentimiento por la naturaleza}

La pasión por la naturaleza, la podemos encontrar en varios de sus textos y obras, entre los que destaca "Du sentiment de la nature dans les societés modernes" publicado en la Reveu de Deux Mondes en 1866, Historia de una montaña (1880), Viaje a la Sierra Nevada de Santa Marta (1861), Historia de un arroyo (1869), entre otros.

En su obra Viaje a la Sierra Nevada de Santa Marta, Reclus manifiesta claramente la armonía indescriptible del paisaje, afirmando:

[...] todo es rítmico en ese pequeño mundo, limitado hacia el continente, pero abierto del lado de las aguas infinitas; todo parece haber seguido lo misma ley de ondulaciones desde las altas montañas de cimas redondas hasta las líneas de espuma, débilmente trazadas sobre la arena. ¡Cuán dulce es contemplar ese admirable cuadro! Se mira, se mira sin cesar, y no se sienten pasar las horas. Sobre todo, en la tarde, cuando el borde inferior del sol principia a sumergirse en el mar y que el agua tranquila viene a suspirar al pie de lo ribera, lo verde explanado, los oscuros valles de la Sierra, las rosadas nubes y las lejanas cimas como salpicadas de polvo de fuego, presentan un espectáculo tan bello, que el viajero absorto parece que no tiene vida sino para ver y admirar. Los que han tenido la dicha de contemplar este grandioso paisaje jamás lo olvidan. (RECLUS, 1861, p. 48)

En su artículo "El sentimiento de la naturaleza en las sociedades modernas", Reclus, además de exaltar la armonía de la naturaleza, se refiere al gran número de hombres que, estimulados por una especie de fascinación e instinto físico, se sienten impelidos a escalar escarpadas montañas, respirar aire puro y admirar el horizonte, el cielo azul y el cinturón de nubes que la circunda $y$, al mismo tiempo, observar sus diferentes zonas climáticas y florísticas (RECLUS, 2010b 
[1866], p. 30-31).

En la afición a escalar las montañas, explica Élisée, está el deseo de respirar "un aire fresco y vivo", que nos hace sentir "renovados", alegrías materiales que se asocian a los placeres intelectuales cuando tenemos oportunidad de observar in situ el trabajo de la erosión del agua y de la nieve, del movimiento de los glaciares y a la vez contemplar las enormes masas de granito con sus contrafuertes, valles y planicies, resultado de una actividad geológica de millares de años y cubiertos por bosques y praderas (RECLUS, 2010b [1866], p. 34-37).

Esta mirada global con la que se contempla la fusión hombre-naturaleza, y que según Reclus produce un doble placer, físico e intelectual que amplía las facultades humanas y produce una profunda sensación de libertad, también se observa en la obra de Humboldt, lectura habitual de Reclus, cuando escribe:

El simple aspecto de la naturaleza, la visión de los campos y los bosques causan un placer que difiere esencialmente de la impresión que produce el estudio particular de la estructura de un ser organizado. Aquí lo que nos interesa es el detalle, que excita nuestra curiosidad; allí, es el conjunto, son las masas las que agitan nuestra imaginación. (HUMBOLDT, 1807, p. 30, apud DELÉAGE, 1993, p. 50)

Bajo el mismo criterio, en los escritos de Reclus los ríos se transforman en un símbolo de movilidad, de vida y de dinamicidad: acción y reacción, y por esto constituyen el elemento que mejor refleja el movimiento de la naturaleza.

En su libro La Historia de un Arroyo, publicado en español como El Arroyo, el sentimiento de amor a la naturaleza de Reclus se manifiesta través de un diálogo con la misma (con el aire, la temperatura, la vegetación ribereña...) en el que analiza, con gran sensibilidad los diferentes paisajes por los que el río surca: desde que nace, brotando de las montañas y adquiriendo paulatinamente dinamicidad a través de sus corrientes, hasta que vuelve a la calma al atravesar las planicies que le transportan a su desembocadura en el mar.

Como geógrafo ácrata (profundamente naturalista y romántico) Reclus valora muchísimo la libertad a punto de afirmar que "el hombre sencillo que se contenta con amar la naturaleza en sí misma, en ella encuentra su alegría, y cuando está infeliz, sus sufrimientos son suavizados por el espectáculo de la libertad en el campo". Citando al conde Rumford (Benjamín Thompson), Reclus escribe "encontramos siempre en la naturaleza más de lo que buscamos" (RECLUS, 2010b [1866], p. 93).

Es en este escenario donde, para Reclus, el ser humano experimenta su relación con el espacio, en el que dialoga con la naturaleza.

\section{El hombre es naturaleza}

Élisée Reclus entiende que "El hombre es la naturaleza adquiriendo conciencia de sí mismo" (El Hombre y la Tierra, 1985 [1905-1908], p. 38-40).

Para el geógrafo francés, la Tierra es un 'organismo vivo', y su naturaleza es la escuela de la humanidad futura, en la que a los seres humanos les corresponde la conciencia de este gigante organismo, es su parte pensante. Esta condición nos atribuye a todos la facultad de utilizar la naturaleza, y a la vez, la responsabilidad de cuidar de la misma, de los demás seres orgánicos e inorgánicos del planeta, porque es de ella, de la Tierra, de donde extraemos nuestra vida.

Sus reflexiones y conceptos recibieron una gran influencia del pensamiento rousseauniano sobre la armonía natural, de las tesis positivistas y evolucionistas y de la dialéctica de Pierre-Joseph Proudhon, vinculada a los principios de la ayuda mutua como motor da humanidad, expresado también por otros anarquistas, como Piotr Kropotkin, Mijaíl Bakunin y León Metchnikoff.

Los principales exponentes de la concepción de base predominantemente naturalista en el ámbito geográfico europeo de la primera mitad del siglo XIX, Humboldt y Ritter, también fueron relevantes para la construcción teórica reclusiana. Mientras Alexander von Humboldt destacó por sus estudios sobre la distribución geográfica de la flora y de la fauna según las zonas bioclimáticas, en amplios territorios que abarcan desde la América hasta la Asia Oriental, Karl Ritter defendió la existencia de un ámbito terrestre dinámico del que el hombre es parte indisociable, y subrayó la importancia de la historia en los estudios geográficos.

Reclus leyó atentamente algunas de las principales obras de Humboldt y de Ritter, entre ellas Cuadros de la naturaleza, Viaje a las regiones equinocciales del Nuevo Continente y el Cosmos (Humboldt) y Geografía general comparada (Ritter) (CAPEL, 2018, p 6). Además, Élisée fue discípulo de Karl Ritter en la Universidad de Berlín, manteniendo relación con él a posteriori y traduciendo al francés varias de sus obras.

Asimismo gran parte de los principios adoptados por Élisée Reclus y otros anarquistas estuvieron asociados a los avances del conocimiento científico del siglo XIX, vinculados principalmente: a) a un mayor conocimiento sobre la distribución de las especies animales y vegetales en los territorios, como resultado del trabajo de grandes expediciones científicas; b) a la revolución en la concepción del tiempo, que desde los trabajos de Lamarck y los descubrimientos de Wallace 
y de Darwin instituyeron nuevos marcos conceptuales sobre la regulación de las poblaciones y la dinámica de sus evoluciones; c) a la reorganización de las relaciones entre las ciencias físicas, químicas y las de los seres vivos, a través de los progresos de la fisiología, de los análisis químicos y de la termodinámica, del surgimiento de la biología, entre otros (DELÉAGE, 1993, p. 45).

En su conjunto este importante avance científico no siempre supuso unanimidad de opiniones. Así, por ejemplo, mientras que el naturalista francés JeanBaptiste Lamarck (1744-1829) comprobó que el aumento de la complejidad de los seres vivos ocurría a lo largo del tiempo, en función de los hábitos adquiridos y transmitidos generacionalmente debido a la acción de las circunstancias y del medio sobre los organismos, sugiriendo que en la naturaleza todo es armonía; por el contrario, las concepciones de Charles Darwin (18091882) y de Alfred Wallace (1823-1913), basadas en estudios de los factores del medio que afectan a las distribuciones geográficas de la fauna y de la flora, defendieron que la lucha por la subsistencia y la selección natural son los motores de la evolución (DELEAGE, 1993, p. 52-58).

Otro referente en las obras de Élisée fue Ernest Haeckel (1834-1919), creador de la expresión 'ecología' en 1866 y defensor de la filosofía monista que daba una visión unificada y equilibrada del universo. Según esta visión, el mundo físico y los seres vivos están hechos de la misma materia; en el mundo, el hombre y los animales tienen el mismo estatuto; la naturaleza es fuente de verdad y debe servir de modelo para la vida de los seres humanos, cuyas sociedades deben organizarse según los principios inspirados en la observación de la naturaleza (DELEAGE, 1993, p. 73-4).

Sin embargo, la visión socio-darwinista de Ernest Haeckel hizo que tanto Reclus, como Piotr Kropotkin (1842-1921) y Lev Metchnikov (1838-1888) no adoptasen ni el término ecología ni su contenido, optando por la expresión "mesología", como la ciencia que estudia las relaciones e influencias recíprocas que unen a los seres vivos con su entorno.

Gran parte de estos enfoques, cuyo tema principal es la naturaleza y los vínculos entre el ser humano y la naturaleza también constituía uno de los fundamentos esenciales del pensamiento ácrata, por el que se ponía énfasis en que la naturaleza es como un todo armónico, regido por leyes que no se deberían transgredir sin ocasionar importantes desequilibrios medioambientales. Estos principios llevaron a Reclus a elaborar planteamientos muy cercanos a lo que entendemos actualmente por ecología:
El hombre, "ser razonable" que tanto gusta de hacer gala de su libre albedrío, no puede sin embargo hacerse independiente de los climas y condiciones físicas de la región que habita. Nuestra libertad, en nuestras relaciones con la Tierra, consiste en reconocer sus leyes para moldar a ellas nuestra existencia. Cualquiera que sea la relativa facilidad de procederes que hayan conquistado nuestra inteligencia y nuestra voluntad propia, no por menos dejamos de ser producto del planeta, atados a su superficie como imperceptibles animálculos, nos vemos arrastrados en todos sus movimientos y dependemos de todas sus leyes... Después de haber sido para el globo, durante mucho tiempo, simples productos apenas conscientes, nos convertimos en agentes más y más activos en su historia (RECLUS, La Terre, 1869, t. II, p. 622, apud GIBLIN, 1986, p. 62).

Enestemarcoteóricoymetodológico, queleacompaña desde su juventud, Reclus reconoce únicamente las leyes de la naturaleza, admitiendo implícitamente que la naturaleza es equilibrada y armoniosa (OYÓN, 2017, p. 17).

Élisée Reclus insiste en la necesidad de formar una conciencia medioambiental. Para que fuera posible crear esta sensibilidad hacia la naturaleza, presenta como condición una mayor aproximación a la misma y al medio natural. Reivindica el incentivo a la innata tendencia del ser humano de vivir cerca de la naturaleza para poder desfrutar de sus efectos beneficiosos. Considera fundamental una educación que esté comprometida con la naturaleza: proporcionando a los educandos prácticas que llevan a la comprensión y al respeto de sus leyes, fomentando de este modo, su amor por la naturaleza.

El desarrollo de la facultad del sentimiento por la naturaleza debería, según Reclus, darse tanto entre los campesinos, que solían adquirirla cuando se alejaban de su territorio natal, cómo en los urbanitas, a través de la educación y el acercamiento a ella, una posibilidad que, según Reclus se amplía con el desarrollo de los medios de comunicación -especialmente el ferrocarril- que ya en el siglo XIX ofrecían una oportunidad para que los contingentes de campesinos que migraban hacia las ciudades volviesen a reencontrarla en el campo (RECLUS, 2010b [1866]).

\section{La acción del hombre sobre la naturaleza}

A demás de esta visión naturalista y romántica de la naturaleza, los análisis reclusianos contienen una relevante crítica sobre la relación entre la sociedad y el ecosistema. Sus manuscritos contemplan este punto de vista desde un proceso dialéctico.

Esta es la principal aportación de Élisée Reclus: 
entender la relación entre los individuos y el medioambiente como una relación dialéctica, en el espacio y también en el tiempo. Él entiende que no sólo el medio influye sobre el ser humano, como se defendía hacía mucho tiempo, sino que a su vez los individuos influyen en el medio a lo largo del tiempo. Es decir, las relaciones entre el ser humano y su entorno no son inmutables, porque varían en un proceso dialéctico de influencia recíproca.

En esta perspectiva, Reclus defiende el proceso evolutivo social a través de diferentes dinámicas que resultan en coyunturas de progreso y retroceso, en los que ocurren una serie de acciones y reacciones, impulsos y trabas, flujos y reflujos, que se desarrollan en una "espiral de la civilización" cuyas curvas se alteran por cada acontecimiento, estrechándose en períodos de retorno a la barbarie y de guerra (retroceso) y ampliándose en períodos de paz y de progreso social (RECLUS, 1880, apud ZAAR, 2015a, p. 18).

Partiendo de este razonamiento, Reclus niega el movimiento lineal y continuo de la historia de la humanidad, concibiéndolo únicamente asociado a esta dinámica y al movimiento de la naturaleza

[...] períodos de reação sucederam-se aos períodos de ação, recuos seguiram-se aos progressos; o avanço geral realizou-se por uma espécie de oscilação, por uma série de idas e vindas, comparável as ondas da maré montante; sempre uma alternância de recuos momentâneos produziu-se na marcha coletiva dos homens (RECLUS, 2010c [1894], p. 82).

Según Reclus, lo que posibilita que este movimiento se produzca en equilibrio constante es que el germen existente en los elementos centrales, a través del que fluye esta dinámica repleta de combinaciones, transformaciones, contradicciones y permanencias, provea la superación que conlleva a una revolución y a una nueva evolución que coexisten a través del tiempo y del espacio, de forma particular y al mismo tiempo general (ZAAR, 2015a, p. 19).

Este enfoque dialectico posibilitó a Reclus concebir que todas las contradicciones, provocan evoluciones históricas en un movimiento contradictorio y que por más importante que sea esta evolución, trae consigo también signos de un retroceso.

Esta orientación metodológica, se observa en todas sus obras no censuradas. En El Arroyo, Reclus plantea los beneficios que los ríos generan a través de la navegación, la pesca, el riego, la instalación de fábricas y molinos, y a su vez subraya, que en muchas ocasiones el ser humano no utiliza los ríos racionalmente, transformándolos en charcas con viscosidades de todos los colores, que alteran su transparencia y cuyo olor fétido se esparce por la atmósfera o se convierte en cloaca, en una repugnante alcantarilla llena de basuras (RECLUS, 1869).

El método de la acción-reacción también le posibilitó constatar que la utilización irresponsable de la naturaleza lleva a desastres medioambientales, como los ocasionados por las grandes crecidas de los ríos.

En su artículo “L'Homme et la Nature. De l'action humaine sur la geographie physique" publicado en 1864 en la Revue des Deux Mondes, más tarde traducido al inglés como Man and Nature, Reclus se empeña en analizar cómo las acciones antrópicas de los siglos XIX y anteriores habían conseguido destruir gran parte de la naturaleza en algunas regiones, pese a que de ella depende su supervivencia.

A pesar de afirmar que, dependiendo del estado social y el progreso de cada pueblo, la acción humana puede dar mayor diversidad al aspecto de la superficie terrestre (territorio), pero también destruir la naturaleza, Reclus elabora un largo análisis de casos que constató personalmente y que denotan, la poca sensibilidad humana hacia la naturaleza.

Al comentar la obra de George Perkins Marsh, Hombre y Naturaleza, Reclus expone: considerada en su conjunto, la humanidad no emergió en absoluto, en relación a la Tierra, de su barbarie primitiva (RECLUS, 2010a [1864], p. 54). A continuación, ofrece múltiples ejemplos de regiones en las que la especie humana, recién llegada abusa de su poder y agota la tierra que le alimenta. Algunos de los ejemplos a los que hace referencia son la desertificación en Oriente Medio, la pérdida de territorios agrícolas en Carolinas y Alabama (EEUU) y el proceso de erosión y desmoronamiento de bloques rocosos en los Alpes franceses, a causa de las precipitaciones sobre las rocas deforestadas (RECLUS, 2010a [1864], p. 54-56).

Aunque disponiendo de registros pluviométricos poco fiables, Reclus ya intuía, como resultado del proceso de desestructuración de los ecosistemas, que las lluvias disminuyen a medida que se talan los bosques y, al revés, se incrementan a medida que se reforestan las regiones. También afirmaba que la tala de los bosques perturba la armonía de la naturaleza, tornando la escorrentía de las aguas más superficial, lo que puede ocasionar importantes riadas (RECLUS, 2010a [1864], p. 57).

Reclus incluía como responsabilidad directa de los individuos las grandes crecidas que se reproducían en el Loire y otros ríos europeos, como resultado de la construcción de diques dispuestos de modo que contrariaban el movimiento natural de las aguas y los sistemas de drenaje.

En sus artículos sobre el río Mississippi, Élisée analiza como las actuaciones realizadas en él -la intervención en 
uno de sus brazos finales, la disecación de marismas y el encauzamiento indiscriminado con diquesestaban siendo catastróficas. Defiende que hay que saber regularizar el río para no destruir el trabajo de la naturaleza, lo que se hace conociendo su funcionamiento y actuando racionalmente sobre él. El ser humano debe solo regular la dinámica de la naturaleza, afirma Reclus (OYON, 2017, p. 115).

Al referirse al clima, Reclus reconoce que la influencia de las ciudades y de la deforestación, ocasionan el aumento de la temperatura debido a la contaminación atmosférica y la falta de vegetación arbórea. Esto es así, según Reclus, porque, como las grandes superficies líquidas (los mares y los océanos), las florestas atenúan las diferencias de temperatura entre las estaciones y su ausencia dota las corrientes atmosféricas de mayor ímpetu.

Su postura contraria a la tala de árboles es contundente. Advierte sobre la pérdida irreparable de bosques estadounidenses, en especial de las gigantescas secuoyas centenarias, provocada por una sociedad demasiado indiferente al destino de las futuras generaciones (RECLUS, 2010a [1864], p. 61).

Respecto a la relación entre la acción humana y la reducción de la fauna salvaje, Reclus alude a la desaparición del mamut de Siberia (Mammuthus primigenius), del gran ciervo de Irlanda (Megaloceros giganteus), de las vacas marinas de Steller (Hydrodamalis gigas). Hace referencia, también a otras especies en peligro de extinción: búfalos, leones, elefantes, rinocerontes, ballenas blancas, focas y un gran número de especies de aves y peces y a la proliferación de insectos, hormigas, termitas, saltamontes, debido a la ausencia de sus predadores naturales. Además, reconoce los problemas causados por la introducción de especies foráneas (invasoras) (RECLUS, 2010a [1864], p. 62).

Sobre la transformación del territorio, y refiriéndose específicamente a los Estados Unidos de Norteamérica, Reclus hubiera preferido que se conservasen sus suaves contornos ondulados en lugar de la devastación indiscriminada del paisaje natural, eliminado numerosos rasgos de la vida salvaje.

Otro dilema medioambiental y social constatado por Reclus es el monocultivo en detrimento de la agricultura diversificada que favorece la reproducción biótica que mantiene el ecosistema y garantiza la supervivencia del campesino (ZAAR, 2015b, p. 78).

Reclus estaba convencido de que únicamente el entendimiento de la dinamicidad del medio natural permitiría su explotación correcta, lo que le lleva a dar mucha importancia al conocimiento correcto de los fenómenos terrestres y del medio natural. Advierte que solamente la comprensión de las interacciones entre los elementos naturales (suelo, clima, vegetación, etc.), posibilita su utilización correcta.

La acción del hombre, tan poderosa para desecar ciénagas y lagos, para nivelar los obstáculos entre los países, para modificar el primer reparto de las especies vegetales y animales, tiene por lo mismo una importancia decisiva en las transformaciones que sufre el aspecto exterior de la tierra. Puede embellecer la Tierra, pero también afearla; según el estado social y las costumbres de cada pueblo, contribuye ora a degradar a la naturaleza ora a transfigurarla. (La Tierra, t. II, p. 748 apud GIBLIN, 1986, p. 62)

Para Reclus el hombre verdaderamente civilizado se funde con el interés de todos y de la propia naturaleza. Transformado en la "conciencia de la tierra", el ser humano digno de su misión asume por esto mismo una parte de responsabilidad en la armonía y en la belleza circundante.

Es desde este planteamiento reclusiano que coincidimos con Simon Springer cuando afirma que Reclus no solo estaba interesado en las relaciones humanas, sino que tenía una visión más amplia en la que enfatizaba el vínculo integral con el medioambiente, sobre todo para restaurar el equilibrio y la igualdad ente los humanos y la biosfera $(2019$, p. 28$)$.

\section{Élisée Reclus, el determinismo geográfico y el darwinismo social}

Horacio Capel, al referirse a la formación ritteriana de Reclus y a las influencias que recibió (Humboldt, Darwin, Haeckel, George Perkins Marsh), afirma "Reclus tenía que ser 'determinista"' (1981, 302-303).

Sin embargo, diferente de Friedrich Ratzel y su 'espacio vital', el método de análisis de Élisée Reclus nos lleva a cuestionar esta afirmación desde algunos matices que analizamos a continuación, a partir de su obra y de estudiosos de la misma.

Con relación a su posible visión de carácter determinista, Paul Boino destaca que mientras los adeptos al determinismo natural consideraban que el desarrollo humano era determinado por el medio de modo indefinido, Reclus demostró que las relaciones entre los individuos y la naturaleza, están lejos de ser también unívocas e imperativas. $Y$ añade que para Reclus las condiciones naturales son más o menos determinantes según el estado de organización de una sociedad (BOINO, 2010 [2008], p. 33).

A su vez, Yves Lacoste (2005) destaca el hecho de que Élisée Reclus contempló como geográficas todas las 
categorías de fenómenos inscritos diferencialmente en la superficie de la Tierra, valorándolos significativamente en sus interacciones y en sus evoluciones históricas.

Asimismo, el entendimiento de Élisée Reclus sobre los procesos evolutivos refuta cualquier enfoque determinista, ya que posee una visión dinámica de las relaciones socioambientales, siempre teniendo muy en cuenta la historia de las civilizaciones. Este concepto integracionista le llevó a insertar en los textos introductorios de los seis volúmenes de su obra L'Homme et la Terra, la siguiente frase "La geografía no es otra cosa sino la historia en el espacio, así como la historia es la geografía en el tiempo" (GIBLIN, 1986, p. 70).

La postura de Reclus con relación al darwinismo, más concretamente al darwinismo social, también es muy clara: se trata de una corriente teórica que al proclamar que la ley de la naturaleza lleva a la destrucción del más débil, difunde una ideología que tiene como objetivo legitimar y oprimir a gran parte de la humanidad, lo que contradice su sueño anarquista de fraternidad humana. En lugar de buscar razones en la competencia y en la lucha por la supervivencia, Reclus reconocía la importancia de la armonía (no exenta de contradicciones), de la cooperación y de la necesidad de la adaptación del hombre al medio natural, aunque sea a costa de su deterioro. Esta también es la postura de otros anarquistas, como Piotr Kropotkin que rechazó el darwinismo social en su obra El Apoyo Mutuo: un factor de evolución y Lev Metchnikov que afirmó que la ciencia natural nos enseña que la asociación es la ley de toda la existencia (La civilisation et les grands fleuves historiques, 1889).

En la misma dirección, al relacionar las leyes de la naturaleza con las relaciones que rigen las sociedades humanas, Reclus afirma:

Invoca-se, contra as reivindicações sociais, o direito do mais forte, e até mesmo o nome respeitado de Darwin serviu, contra sua vontade, para defender a causa da injustiça e da violência......... "Vede", dizem eles (os naturalistas) "é a lei fatal; é o imutável destino, ao quais devoradores e devorados estão igualmente submetidos". (RECLUS, 2002 [1891], p. 97)

Estas son algunas de las posturas reclusianas, a partir de las que Yves Lacoste afirma

Si el darwinismo social tuvo una gran influencia sobre los geógrafos alemanes, Reclus se recusa a admitir la lucha por la vida como una ley natural fundamental. Sus ideas políticas lo llevan a condenar las formas de opresión y enfatizar que ellas también existen entre los pueblos oprimidos. (2005)
Otro aspecto a tener muy presente es que el determinismo está en contra de la libertad de acción de los individuos porque esta libertad rompe con la idea de un ser humano que no encuentra obstáculos a su 'progreso' ya que ejerce un dominio absoluto sobre la naturaleza (RIBAS RABASSA, 2003, p. 78). Sin embargo, la metodología y la obra de Reclus, basada en los principios ácratas, exalta la libertad humana y "defiende que la sociedad y la naturaleza forman un conjunto armónico" (ZAAR, 2015a, p. 5), lo que nos lleva a creer que los conceptos reclusianos contradicen el determinismo geográfico.

Con relación al medio-espacio, Reclus resalta que el ser humano debe comprender el funcionamiento del medio (naturaleza-equilibrio natural) para saber actuar sobre el mismo y preservar su equilibrio; y por medio-tiempo, sostiene que las condiciones naturales pueden ser más o menos determinantes en el tiempo, dependiendo de la organización social de los agrupamientos humanos y de sus posibilidades de intervenir sobre los recursos naturales (RECLUS, 1986 [1906-1908], p. 102-105; RECLUS, 1985 [1906-1908], p. 57-60).

Se trata de conceptos que integran medio y tiempo y que indican claramente la poca importancia que tiene el determinismo geográfico en su obra. Por el contrario, deja muy claro que la influencia de un determinado factor en la sociedad puede evolucionar y hasta cambiar totalmente, en función de la capacidad de la misma de mejorar su control sobre estos factores. Para Reclus, el hecho de que una unidad geográfica, como un rio, anteriormente considerado una barrera, se transforme en un medio de comunicación y de transporte, prueba que las interacciones entre los elementos humanos y naturales de un determinado espacio están en permanente evolución y superación, impulsadas por el avance de la civilización y de los elementos que la integran (ZAAR, 2015a, p. 25)

Es a partir de esta doble dimensión, desde la que rechaza tanto el determinismo geográfico como el darwinismo social, que Reclus elabora sus análisis de las prácticas sociales (económicas, militares o políticas) desde una visión geográfica:

Al medio-espacio, caracterizado por los miles de fenómenos exteriores hay que agregar el mediotiempo, con sus transformaciones incesantes, sus repercusiones $\sin$ fin. Si la historia comienza primero por ser "toda geografía", como dice Michelet, la geografía se vuelve gradualmente "historia" por la reacción continua del hombre sobre el hombre. El tiempo modifica incesantemente el espacio. (RECLUS, 1986 [1906-1908], p. 102-105; RECLUS, 1985 [19061908], p. 57-60) 
Asimismo, las cuatro dimensiones reclusianas, Individuo, Sociedad, Espacio y Tiempo (ZAAR, 2015a) concebidas a partir de una unidad, representan, según Ronaldo Creagh, mucho más que simples parámetros. Asumen dimensiones épicas:

0 espaço faz-se sinfônico, transforma-se em um hino à natureza; o tempo desposa a sociedade, pois quando esta sai do seu isolamento se torna mais complexa; a mudança linear da história se transforma em uma ascensão espiral. Em resumo, a crescente complexidade que se observa na evolução da Terra e de seus seres vivos aplica-se também à humanidade. E o indivíduo, que não pode ser passivo, é o agente dessas novas harmonias (CREAGH, 2010, p. 16).

Con base en este razonamiento, y después de estos argumentos, si alguien quiere hacer hincapié en algunos rasgos deterministas que comprenden las primeras obras de Reclus, podemos recurrir a las palabras de Ribas Rabassa que considera que el determinismo de Reclus posee importantes matices, lo que no desmerece en nada sus apelaciones éticas a favor de la libertad del individuo, de la distribución equitativa de los recursos o de un replanteamiento del dominio destructivo del ser humano sobre la naturaleza. "Ni tampoco sus aportaciones científicas acerca de la relación dialéctica entre el hombre y la naturaleza o sobre la importancia de tener en cuenta el factor tiempo al analizar esa relación" (RIBAS RABASSA, 2003, p. 78).

Sobre estas últimas Ribas Rabassa afirma:

En primer lugar, por esa relación dialéctica entre hombre y medio en la que no sólo el medio modifica al hombre, sino que también el hombre modifica al medio. Aunque la verdad es que a muchas de las acciones humanas que transforman el medio Reclus les atribuye una explicación determinista. Como se puede ver se trata de un todo integrado en el que las influencias se suceden. $(2003$, p. 81$)$

Ribas señala igualmente que Reclus prevé que el progreso cultural y técnico hará que el ser humano domine la naturaleza. Estas afirmaciones se encuentran tanto en su Nouvelle Géographie Universelle como en L'Homme et la Terre, obras en las que señala que, favorecido por nuevas tecnologías, el ser humano, ya había dominado la naturaleza. Una visión compartida por Karl Ritter.

Independiente de la faceta reclusiana que se quiera considerar, es esencial tener en cuenta sus estudios metodológicos, que consiguen captar como las diferentes variables del espacio son modificadas y superadas en un movimiento protagonizado por la acción humana en su conjunto, y por los fenómenos climáticos a través de escalas temporales desiguales:

El medio es siempre infinitamente complejo y el hombre, por consiguiente, se ve solicitado por millares de fuerzas diversas que se mueven en todos sentidos, formando agregando las unas con las otras, éstas directamente, aquéllas según ángulos más o menos oblicuos, o contrariando mutuamente su acción (RECLUS, 1986 [1906-1908], p. 101; RECLUS, 1985 [1906-1908], p. 57).

Sobre la metodología desarrollada por Reclus y refiriéndose a un extremo suyo, a primera vista determinista (o ecologista profundo), pero que va siempre acompañado de otro extremo activo y transformador, Oyón sostiene que, desde el primer texto escrito por Reclus con solo veinte años, la acción de la Tierra sobre el hombre fue contrarrestada por una reacción igualmente decisiva de este sobre aquélla. Avala: "Entre el hombre y la tierra hay constante acción y reacción mutua, hay una dialéctica histórica" (OYÓN, 2017, p. 256).

A su vez, Philippe Pelletier (2010) afirma que, aunque Reclus no está exento de tendencias biologizantes y organicistas, éstas suponen una figura de estilo, una utilización de la metáfora, antes que una toma de posición en cuanto a su fundamento. Su geografía, naturalista y humana, se torna clara en el apogeo de su reflexión social.

Además, Pelletier se ocupa de comparar la geografía de Élisée Reclus con la geografía de Vidal de la Blache. Esta es su apreciación: "La dialéctica reclusiana del medio-espacio y del medio-tiempo se distingue de la perspectiva lablachiana 'medio y tipo de vida'. Aquella parece mucho más pertinente, mucho más rica" (2010, p. 17).

Esta postura refleja, ante todo, que Reclus no fue un geógrafo determinista. Sus reflexiones señalan la importancia de la dinámica "acción y reacción" entre el ser humano y los elementos físicos de su entorno en las grandes coyunturas históricas. Demuestra "que el medio físico no gobierna, no determina la organización económica y social de los grupos humanos" (GIBLIN, 1986, p. 77).

Esta también es la postura de Paul Boino cuando afirma: "Antideterminista, Reclus funda una geografía que tiene como función analizar el mundo como es, es decir, un sistema complejo formado por elementos interdependientes que conviene aprehender, en esta perspectiva, como medio" (BOINO, 2010a, p. 30).

Reclus, un proto-ecologista

Daniel Hiernaux-Nicolas expone en la introducción de 
la obra La geografía como metáfora de la libertad. Textos de Élisée Reclus que este fue un geógrafo adelantado en su tiempo, un geógrafo global que nos invita a conocer un mundo complejo, contrastado, pero unificado por grandes procesos centrales (1999, p. 15).

A su vez, Ronald Creagh cree que el gran aliento que inspiró la grandiosa obra de Élisée Reclus se encuentra modulado por la multiplicidad de puntos de vista en el microanálisis, sin que ninguna idea destaque de su contexto (CREAGH, 2010, p. 23).

Desde este marco analítico consideramos que, aun teniendo en cuenta que el contexto económico y medioambiental fuera otro, y todavía no se tenían presentes los problemas actuales, las concepciones y los métodos de estudio de Reclus y de otros pensadores ácratas nos proporcionan pistas muy significativas de sus preocupaciones con lo que denominamos actualmente "ecosistema", objeto de estudio de la ecología.

El afán de Reclus de estudiar el medio desde sus diversos elementos y perspectivas, y de subrayar los límites de la naturaleza, advirtiendo insistentemente que no deben ser traspasados, debido a que llevarían al agotamiento de los recursos naturales, a la contaminación atmosférica y fluvial y a cambios en el ecosistema local y regional, lo convierte en un proto-ecologista.

También contribuye a que Reclus sea considerado un proto-ecologista, su teoría de que la naturaleza y el ser humano forman un conjunto que coexiste en un proceso complejo y pleno de movimientos contradictorios que se atraen y se repelen en una dinámica, desde la que alerta sobre la estrecha relación entre el uso indebido de la naturaleza y su destrucción.

Setrata de procesos que Reclus analizó detenidamente y desde los que dedujo que habría consecuencias a medio y largo plazo, razonando que, cuando se actúa sobre uno de los elementos del medio natural se desencadena automáticamente una modificación de su dinámica, lo que conduce a un nuevo equilibrio o a un desequilibrio en sus interacciones, dependiendo de la acción llevada a cabo.

Asimismo, sus conocimientos del medio le llevaron a reivindicar responsabilidades en las actuaciones humanas sobre el mismo. Por un lado, Élisée reivindica como precondición para cualquier intervención en la naturaleza, su conocimiento detallado con el fin de dañar lo menos posible su supervivencia como tal, llegando a afirmar que el aumento de las posibilidades de intervención humana a través del uso de técnicas y máquinas puede provocar graves desequilibrios medioambientales, si estas no son adecuadas.

Por otro lado, Reclus propone medidas vinculadas a lo que denominamos actualmente 'economía circular', cómo el aprovechamiento de los detritos orgánicos para abonar los campos.

En su conjunto, es a partir de estas concepciones, caracterizadas por lo que se podría denominar como una conciencia ecológica que advierte de los riesgos de la depredación de los ecosistemas por la acción humana, que investigadores como Béatrice Giblin confieren a Élisée Reclus la calificación de ecologista precoz, y de algún modo precursor del desarrollo sostenible.

Esta postura reclusiana a favor de la protección medioambiental ganó fuerza solamente medio siglo después de su muerte, a través de la primera ola ecologista, de la que fueron protagonistas el historiador de inspiración anarquista Murray Bookchin (19212006), fundador de la ecología social con obras como Nuestro Entorno Sintético (1962) que trata de la colisión catastrófica de la humanidad contra el mundo natural, o Crisis en Nuestras Ciudades (1965), y también otros investigadores como el biólogo y activista político Barry Commoner (1917-2012) a través de sus obras Ciencia y Supervivencia (1966) y El círculo que se cierra (1971).

Para contrarrestar el proceso de deterioro medioambiental, Reclus elaboró propuestas basadas en la construcción de otro tipo de sociedad, lo que, según su pensamiento, solo se podría lograr a través de la concienciación.

Reclus tenía claro que el acercamiento de los individuos a la naturaleza era fundamental para comprenderla, y para promover reflexiones y cambios de actitud respecto al metabolismo urbano asociado a reducción del consumo del agua, de energía y de otros materiales, con el objetivo de disminuir los residuos atmosféricos y fluviales.

La gran aportación ecológica de Reclus fue proponer una vía distinta en la discusión sobre las relaciones sociedad-naturaleza, mediante la que vislumbra la construcción de un modelo de sociedad capaz de convivir armoniosamente con la naturaleza; o sea, se decanta por una geografía con tintes ecológicos que inspiró a muchos geógrafos del siglo XX. Para Reclus, el 'sentimiento de naturaleza' es esencial para que los individuos no solo tomen conciencia de la importancia de esta, sino que aprendan a convivir mejor con su entorno natural.

Es por las razones que hemos expuesto aquí que Reclus merece ser recordado por sus magníficas contribuciones científicas en muchos campos del conocimiento, aunque, consideramos que su legado intelectual más duradero es la aportación que brinda al desarrollo de una visión ecológica del mundo y en particular al razonamiento ecológico-social.

Sus ideas, en gran parte elaboradas bajo la influencia del pensamiento ácrata, pudieron poner al 
descubierto el origen de la alienación humana respecto a la naturaleza y su estímulo para dominarla, y al mismo tiempo consiguieron reposicionar al ser humano en su debido lugar, el que le corresponde: el ser humano es la naturaleza adquiriendo conciencia de sí mismo.

Este es, de un modo sucinto, un examen sobre la valiosa contribución de Élisée Reclus al conocimiento del medioambiente en el siglo XIX y fuente de inspiración para geógrafos y demás investigadores comprometidos con un proceso que ha de llevarnos a una evolución social, desde la que seamos capaces de entender y respectar la naturaleza, que es el ecosistema del que dependemos para nuestra supervivencia. Su pertinencia y actualidad nos lleva a considerarlo, un 'geógrafo completo' por la gran cantidad de temas que estudió, y además lo reconocemos como un proto-ecologista. 


\section{Referências}

BOINO, Paul (2010) O pensamento de Élisée Reclus. RECLUS, Élisée. Da ação humana na geografia física. Geografia comparada no espaço e no tempo. Organização e tradução Plínio Augusto Coelho. São Paulo: Editora Imaginário/ Expressão \& Arte Editora. Publicación original: Introducción. Élisée Reclus. París: Les Éditiones Libertaires, 2008. BOOKCHIN, Murray (1965) Crisis in our cities. (published under the pseudonymn "Lewis Herber"). New Jersey: PrenticeHall.

BOOKCHIN, Murray (1975) Our Synthetic Environment. New York: Knopf (published under the pseudonymn "Lewis Herber"). London: Harper \& Row.

CAPEL, Horacio (1981) Filosofía y ciencia en la Geografía contemporánea. Barcelona: Barcanova.

CAPEL, Horacio (2018) Reclus Revisitado. Biblio3W. Revista Bibliográfica de Geografía y Ciencias Sociales. Barcelona, Universidad de Barcelona, vol. XXIII, no 1.229 <http://www.ub.edu/geocrit/b3w-1229.pdf>.

COMMONER, Barry (1996) Science and Survival. New York: Viking.

COMMONER, Barry (1973) El círculo que se cierra. Barcelona: Plaza \& James.

CREAGH, Ronaldo (2010) Reclus, ou a grande narrativa da Terra. RECLUS, Élisée. Do sentimento da natureza nas sociedades modernas. Organização e tradução Plínio Augusto Coelho. São Paulo: Editora Imaginário/ Expressão \& Arte Editora.

DELÉAGE, Jean Paul (1993) Historia de la Ecología. Una ciencia del hombre y la naturaleza. Barcelona: Icaria.

GIBLIN, Béatrice (1986) Anarquía y leyes naturales. RECLUS, Élisée. El Hombre y La Tierra. Introducción y selección de textos Béatrice Giblin. México: Fundo de Cultura Económica, p. 61-62.

GIBLIN, Béatrice (1986) Una sensibilidad ecológica RECLUS, Élisée. El Hombre y La Tierra. Introdução e seleção de textos Béatrice Giblin. México: Fundo de Cultura Econômica, p. 62-64.

GIBLIN, Béatrice (2005) Élisée Reclus, un geógrafo excepcional. Hérodote: Revue de géographie et de géopolitique, $\mathrm{n}^{\circ}$ 117, p. 11-28 <https://dialnet.unirioja.es/ejemplar/114177>.

HIERNAUX-NICOLAS, Daniel (1999) Introducción. La geografía como metáfora de la libertad. Textos de Élisée Reclus. Selección y presentación de Daniel Hiernaux-Nicolas. Ciudad de México: Centro de Investigación Científica Ing. Jorge L. Tamaio/Plaza y Valdes Editores.

KROPOTKIN, Piotr (2005). El Apoyo Mutuo: un factor de evolución. Santiago, Chile: Instituto de Estudios Anarquistas, < https://web.resist.ca/ crisxyz/iea/biblioteca/pdf/Kropotkin.El\%20apoyo\%20mutuo.pdf>

LACOSTE, Yves (2005) Élisée Reclus, une très large conception de la géographicité et une bienveillante géopolitique. Hérodote: Revue de géographie et de géopolitique, $\mathrm{n}^{\circ}$ 117, p. 29-52 <https://www.herodote.org/spip.php?article149> OYÓN, José Luis (2017) La ciudad en el joven Reclus 1830-1871. Hacia la fusión naturaleza-ciudad. Barcelona: Ediciones del Viaducto.

PELLETIER, Phillippe (2010) A cidade e a geografia urbana em Élisée Reclus e sua época. RECLUS, Élisée. Renovação de uma cidade. Repartição dos homens. Organização e tradução Plínio Augusto Coelho São Paulo: Editora Imaginário/ Expressão \& Arte Editora.

RECLUS, Élisée (s/f) El Arroyo. Traducción de A. López Rodrigo. Valencia: F. Sempere y C. Editores <https:// periodicohumanidad.files.wordpress.com/2009/01/el-arroyo.pdf>.

RECLUS Éliseé (1861). Viaje a la Sierra Nevada de Santa Marta. Biblioteca Popular de Cultura Colombiana, Tomo 112. <https://jjmlsm.files.wordpress.com/2015/10/eliseo-reclus-viaje-a-la-sierra-nevada-de-santa-marta.pdf>.

RECLUS, Elisée (1866) L'Homme et la nature. De l'action humaine sur la geographie physique, Revue des Deux Mondes, Vol. 63, p. 352-381 <http://classiques.uqac.ca/classiques/reclus_elisee/sentiment_nature_soc_modernes/sentiment_ nature_soc_mod.pdf>.

RECLUS, Élisée (1985) O Homem é a natureza adquirindo consciência de si própria. ANDRADE, Manuel Correia de; FERNANDES, Florestan (Org. y Coord.). Reclus Élisée. São Paulo: Editora Ática, p. 38-40. Título original: Préface. L'homme est la nature prenant conscience d'elle-mêsme. L'homme et la Terre, 1905-1908, tomo I.

RECLUS, Élisée (1986) El Hombre y la Tierra. Introducción y selección de textos de Béatrice Giblin. Ciudad de México: Fondo de Cultura Económica. Título original: L'homme et la Terre. Paris, 1982. La obra completa fue publicada entre 1906 y 1908 por la Librairie Universelle de Paris.

RECLUS, Élisée (2002) A evolução, a revolução e o ideal anarquista. Traducción Plínio Augusto Coelho. São Paulo: Editora Imaginário/ Expressão \& Arte Editora. Título original: Evolution et révolution. París: Al bureau de la Révolte, 1891. Organizado a partir de una conferencia impartida en Ginebra en febrero de 1880. 
RECLUS, Élisée (2010a) Da ação humana na geografia física. Geografia comparada no espaço e no tempo. Organización y traducción Plínio Augusto Coelho. São Paulo: Editora Imaginário/ Expressão \& Arte Editora. Título original: De l'action humaine sur la géographie physique. Géographie comparée dans l'espace et dans le temps, Revue des Deux Mondes, Vol 54, 15 de diciembre de 1864, p. 762-771 <https://journals.openedition.org/bibnum/473>.

RECLUS, Élisée (2010b) Do sentimento da natureza nas sociedades modernas. Organización y traducción Plínio Augusto Coelho. São Paulo: Editora Imaginário/ Expressão \& Arte Editora. Título original: Du sentiment de la nature dans les sociétés modernes, La Revue des Deux Mondes, tomo 63, Paris, 1866.

RECLUS, Élisée (2010c) Algumas palavras de História. RECLUS, Élisée. Suas guerras e seu projeto de federação. Organización y traducción Plínio Augusto Coelho. São Paulo: Editora Imaginário/ Expressão \& Arte Editora. Título original: Quelques mots d'histoire, La Société Nouvelle, tomo 2, 1894.

RECLUS, Élisée (2015) O Homem e a Terra. Textos escolhidos. Selección y traducción Plínio Augusto Coelho. São Paulo: Intermezzo.

RIBAS RABASSA, Pere (2003) L'homme et la terre. Las relaciones hombre-medio en el pensamiento de Elisée Reclus (1830-1905). DOSSIER-2003 [ISSN 1696-4403] <https://ddd.uab.cat/pub/hmic/16964403n1/16964403n1p71.pdf>.

SPRINGER, Simon (2019) Las raíces anarquistas de la geografía. Hacia la emancipación espacial. Traductor: Gerónimo Barrera de la Torre. Ciudad de México: Instituto de Geografía, Universidad Nacional Autónoma de México <http://www. publicaciones.igg.unam.mx/index.php/ig/catalog/book/164>.

ZAAR, Miriam Hermi (2015a) Élisée Reclus e o seu método geográfico. Biblio 3W. Revista Bibliográfica de Geografía y Ciencias Sociales, Barcelona, Universidad de Barcelona, Vol. XX, n $1123<$ <ttp://www.ub.edu/geocrit/b3w-1123.pdf>. [ISSN 1138-9796].

ZAAR, Miriam Hermi (2015b) A questão agrária na obra geográfica de Élisée Reclus. Ateliê Geográfico, Goiânia, 9 (3), p. 43-62. [DOI 10.5216/ag.v9i3.37627] <https://doi.org/10.5216/ag.v9i3.37627>. 